\title{
Management of Spontaneous Superficial Intracerebral Hematomas
}

\author{
Mohamed Mahmoud, Ahmad Elsayed Abokresha \\ Department of Neurosurgery, Assiut University Hospital, Assiut, Egypt \\ Email:msmluxor@yahoo.com, ahabokreshaa@gmail.com
}

How to cite this paper: Mahmoud, M. and Abokresha, A.E. (2020) Management of Spontaneous Superficial Intracerebral Hematomas. Open Journal of Modern Neurosurgery, 10, 208-221.

https://doi.org/10.4236/ojmn.2020.102022

Received: December 23, 2019

Accepted: February 18, 2020

Published: February 21, 2020

Copyright $\odot 2020$ by author(s) and Scientific Research Publishing Inc. This work is licensed under the Creative Commons Attribution International License (CC BY 4.0).

http://creativecommons.org/licenses/by/4.0/

(c) (i) Open Access

\section{Abstract \\ Background: Treatment of primary spontaneous superficial intracerebral} hemorrhage (SSICH) is still controversial. The aim of this study is to investigate the effectiveness of craniotomy and early hematoma evacuation vs conservative (non operative) management in patients with SSICH. Methods: A prospective study of craniotomy and early hematoma removal vs. medical management was performed in 20 patients with cortical and subcortical (superficial) primary SSICH admitted to Assiut university hospital in one year period (March 2016-March 2017). Surgical or medical treatment was initiated immediately when patients admitted to hospital. We divided the patients into two groups according to type of treatment. Results: Age of the patients ranged from 2 months to 73 years (mean: $45.84 \pm 23.28$ years) among the 20 patients studied; 13 (65\%) were males and $7(35 \%)$ were females. Glasgow coma scale (GCS) at admission was less than 8 in 25\%, between $8-12$ in $45 \%$ and 15 in $30 \%$ of the patients. Arterial hypertension was the most common associated medical disease (65\%). Eleven of patients (55\%) had ventricular extension. GCS at admission was the strongest factor affecting outcomes and determined the type of treatment. All patients with a GCS $\leq 8$ ( 5 cases $(25 \%)$ were died regardless the type of treatment and there was no significant statistical difference in this group in relation to type of treatment p-value (0.606). We had 6 cases (30\%) with a GCS 15; all of them were treated conservatively and all of them survived with significant p-value (0.003). Nine patients (45\%) had GCS 8 - 12; two of them were treated conservatively and died while the remaining seven patients were treated surgically; five of them survived with significant $\mathrm{p}$-value (0.025). No significant statistical difference was found in the outcome between the surgical and the conservative group regarding having associated intracranial hemorrhage. Conclusions: After analyzing the results, we found that when the GCS is " $8-12$ ", surgical intervention is recommended and carried a better prognosis than waiting for the conservative treatment. When GCS is higher ">12", conservative treatment can be the fa- 
vorable option. Otherwise, we found no statistical difference between surgical and conservative treatment in the treatment of ICH.

\section{Keywords}

Craniotomy, Intracerebral Hemorrhage, Medical Management, Outcome, Surgical Treatment

\section{Introduction}

We have come a long way since Charcot and Bouchard first described intracerebral hemorrhage (ICH) in 1868 [1]. ICH accounts for approximately $10 \%$ of all strokes and is defined as non traumatic abrupt onset of severe headache, altered level of consciousness, and/or focal neurological deficit that is associated with a focal collection of blood within the blood parenchyma on neuro-imaging or autopsy and is not caused by trauma or hemorrhagic conversion of a cerebral infarction [2].

Non traumatic intracerebral hemorrhage (ICH) represents cerebral parenchymal bleeding that may also extend into ventricular, and rarely, subarachnoid space. ICH, as a stroke subtype, is associated with poor neurological outcome as well as high mortality (about 40\% per month) [3]. Spontaneously, non-traumatic intracerebral hemorrhage (ICH) remains a significant cause of morbidity and mortality throughout the world. Primary intracerebral hemorrhage (ICH), i.e. spontaneous extravasation of blood into the brain parenchyma, begins very suddenly and is a medical catastrophe. After the onset, bleeding may continue and the hematoma grows for several hours, leading to progressive clinical deterioration of the patient's condition. Computed tomography (CT) soon after the onset of symptoms is crucial for the diagnosis. Urgent emergency procedures and intensive care are often needed. Six risk factors for ICH have been identified, age, male sex, race, hypertension, high alcohol intake, and low serum cholesterol. Regarding other possible risk factors, current or past smoking and diabetes mellitus are weak risk factors, if at all [4].

Case fatality is high, as $35 \%-52 \%$ of patients die within 30 days and half of the deaths occur in the first two days. Up to $58 \%$ of survivors have been reported to be functionally independent at 1 year [5]. Hypertension and amyloidal angiopathy account for $78 \%-88 \%$ of primary hemorrhages [6]. Although ICH has traditionally lagged behind ischemic stroke and aneurysmal subarachnoid hemorrhage in terms of evidence from clinical trials to guide management, the past decade has seen a dramatic increase in studies of ICH intervention. Population-based studies show that most patients present with small ICHs that are readily survivable with good medical care. This suggests that excellent medical care likely has a potent direct impact on ICH morbidity and mortality [7]. No effective or definitive treatment exists and there remains a lack of data demonstrating 
the efficacy of surgery [8].

The aim of this study is to investigate the effectiveness of craniotomy and early hematoma evacuation vs conservative (non operative) management in patients with SICH.

\section{Patients and Methods}

Clinical data of all patients with primary superficial (cortical and subcortical) supratentorial ICH admitted to department of neurosurgery, Assiut university hospital between March 2016 and March 2017 were prospectively collected. The study was approval from the research ethics committee of the faculty of medicine at Assiut university (reference number: IRB00008718 at 23 October 2016.) was obtained. Informed consent for medical or surgical intervention was obtained from all patients or their relatives. Cerebellar, basal ganglonic hemorrhages and secondary ICH (vascular causes such as aneurysms, tumors and arterio-venous malformation, and that secondary to trauma) were excluded. After confirming the diagnosis with computed tomography, all patients were allocated into one of the two main treatment groups: 1) early surgery (10 patients) and 2) conservative treatment (10 patients), choosing the line of treatment was designed according the clinical presentations of the patients especially the GCS, when the patient has minor symptoms and signs, conservative line was selected if the patients with conservative treatment developed progressive deterioration in conscious level or neurological state or shows hematoma expansion, surgical management was considered The selection guidelines for early surgery include: coma or progressive deterioration of the level of consciousness, progressive neurological deficits and/or hematoma expansion that noticed on follow up C.T. scan. We assessed the effectiveness of craniotomy and early hematoma evacuation vs conservative (nonoperative) management by comparing the postoperative and follow up data to the preoperative data.

Data analysis:

The results were managed by using Statistical Package for the Social Sciences (SPSS) to analysis the variables Chi-square test was used for statistical analysis. Probability values of $(\mathrm{P}<0.05)$ were considered statistically significant.

\section{Results}

Twenty patients were included in these studies. They were admitted to Assiut university hospital from March 2016 to March 2017. They were 13 males (65\%) and 7 females (35\%). The age of the patients ranged from 2 months to 73 years (mean: $45.84 \pm 23.28$ years).

Nine of our patients were below age of 50; three of them were treated conservatively while six of them were treated surgically. Eleven cases were above or equal age of 50, seven of them were treated conservatively while the remaining four patients were underwent surgery. We found no statistic significant differences in outcome between the 2 groups regarding age and gender as shown in 
Table 1.

The most common presentation at admission was disturbance in conscious level (DCL) in 12 out of 20 cases (60\%) as shown in Table 2.

As described in Table 3 and Table 4, all our patients with a GCS $\leq 8$ (5 cases (25\%) were died regardless the type of treatment and there was no significant statistical difference in this group in relation to type of treatment p-value (0.606), we had 6 cases (30\%) with a GCS 15 all of them were treated conservatively and all of them survived with significant p-value (0.003). Regarding GCS 8 12 , we had 9 patients (45\%), two of them were treated conservatively and died while the remaining seven patients were treated surgically, five of them survived with significant $\mathrm{p}$-value (0.025).

We found no significant statistical difference in the outcome between the surgical and the conservative group regarding having associated intracranial hemorrhage as shown in Table 5 .

We had 4 out of 20 patients (20\%) developed complications, 2 cases had chest infection (10\%) one patient had pulmonary embolism (5\%) and one patient (5\%) had renal failure. Table 6 shows that the frequency of complication in relation to type of treatment was slightly more in surgical management 3 of 4 cases (75\%) than in conservative management 1 of 4 cases (25\%), but with no statistical significant difference.

Table 1. Relationship between type of treatment and gender and age.

\begin{tabular}{|c|c|c|c|c|c|c|c|c|c|c|}
\hline \multirow{4}{*}{ Personal data } & \multirow{4}{*}{ NO } & \multicolumn{8}{|c|}{ Type of treatment } & \multirow{4}{*}{ p-value } \\
\hline & & \multicolumn{4}{|c|}{$\begin{array}{l}\text { Conservative } \\
\quad(n=10)\end{array}$} & \multicolumn{4}{|c|}{$\begin{array}{l}\text { Surgical craniotomy } \\
\qquad(\mathrm{n}=10)\end{array}$} & \\
\hline & & \multicolumn{2}{|c|}{$\begin{array}{l}\text { survival } \\
(n=6)\end{array}$} & \multicolumn{2}{|c|}{$\begin{array}{l}\text { Dead } \\
(n=4)\end{array}$} & \multicolumn{2}{|c|}{$\begin{array}{l}\text { survival } \\
(\mathrm{n}=5)\end{array}$} & \multicolumn{2}{|c|}{$\begin{array}{l}\text { Dead } \\
(n=5)\end{array}$} & \\
\hline & & No. & $\%$ & No. & $\%$ & No. & $\%$ & No. & $\%$ & \\
\hline \multicolumn{11}{|l|}{ Age: (years) } \\
\hline$<50$ & 9 & 3 & 33.3 & 0 & 0.0 & 2 & 22.2 & 4 & 44.4 & 0.178 \\
\hline$\geq 50$ & 11 & 3 & 27.3 & 4 & 36.4 & 3 & 27.3 & 1 & 9.1 & \\
\hline \multicolumn{11}{|l|}{ Sex: } \\
\hline Male & 13 & 4 & 30.8 & 2 & 15.4 & 3 & 23.1 & 4 & 30.8 & 0.639 \\
\hline Female & 7 & 2 & 28.6 & 2 & 28.6 & 2 & 28.6 & 1 & 14.3 & \\
\hline
\end{tabular}

Table 2. Clinical presentation of studied patients at admission.

\begin{tabular}{ccc}
\hline Presentation: & $\%$ & No. $(\mathbf{n}=\mathbf{2 0})$ \\
\hline DCL & 60.0 & 12 \\
DCL + Fits & 10.0 & 2 \\
Fits Only & 5.0 & 1 \\
Headache only & 15.0 & 3 \\
Headache + vomiting & 10.0 & 2 \\
\hline
\end{tabular}


Table 3. Relationship between GCS and type of treatment to the outcome.

\begin{tabular}{|c|c|c|c|c|c|c|c|c|c|c|c|c|}
\hline \multirow{4}{*}{ GCS } & \multirow{4}{*}{ NO } & \multicolumn{10}{|c|}{ Type of treatment } & \multirow{4}{*}{ P-value } \\
\hline & & \multirow{3}{*}{ No. } & \multicolumn{4}{|c|}{$\begin{array}{l}\text { Conservative } \\
(\mathrm{n}=10)\end{array}$} & \multicolumn{5}{|c|}{$\begin{array}{l}\text { Surgical craniotomy } \\
\qquad(\mathrm{n}=10)\end{array}$} & \\
\hline & & & \multicolumn{2}{|c|}{$\begin{array}{c}\text { Survival } \\
(n=6)\end{array}$} & \multicolumn{2}{|c|}{$\begin{array}{l}\text { Dead } \\
(n=4)\end{array}$} & \multirow[t]{2}{*}{ No. } & \multicolumn{2}{|c|}{$\begin{array}{l}\text { Survival } \\
(\mathrm{n}=5)\end{array}$} & \multicolumn{2}{|c|}{$\begin{array}{l}\text { Dead } \\
(n=5)\end{array}$} & \\
\hline & & & No. & $\%$ & No. & $\%$ & & No. & $\%$ & No. & $\%$ & \\
\hline$<8$ & 5 & 2 & 0 & 0.0 & 2 & 100.0 & 3 & 0 & 0.0 & 3 & 100.0 & 0.606 \\
\hline $8-12$ & 9 & 2 & 0 & 0.0 & 2 & 100.0 & 7 & 5 & 71.4 & 2 & 28.6 & $0.025^{\star}$ \\
\hline$>12$ & 6 & 6 & 6 & 100.0 & 0 & 0.0 & 0 & 0 & 0.0 & 0 & 0.0 & $0.003^{*}$ \\
\hline
\end{tabular}

Table 4. Relationship between patient outcome and admission GCS.

\begin{tabular}{|c|c|c|c|c|c|c|}
\hline \multirow{3}{*}{ GCS } & \multirow{3}{*}{ No. } & \multicolumn{4}{|c|}{ Outcome } & \multirow{3}{*}{$P$-value } \\
\hline & & \multicolumn{2}{|c|}{$\begin{array}{l}\text { Survival } \\
(\mathrm{n}=11)\end{array}$} & \multicolumn{2}{|c|}{$\begin{array}{c}\text { Dead } \\
(n=9)\end{array}$} & \\
\hline & & No. & $\%$ & No. & $\%$ & \\
\hline$<8$ & 5 & 0 & 0.0 & 5 & 100.0 & $0.008^{\star}$ \\
\hline $8-12$ & 9 & 5 & 55.6 & 4 & 44.4 & 0.964 \\
\hline$>12$ & 6 & 6 & 100.0 & 0 & 0.0 & $0.014^{*}$ \\
\hline Mean \pm SD & & \multicolumn{2}{|c|}{$12.18 \pm 3.25$} & \multicolumn{2}{|c|}{$6.22 \pm 1.99$} & $0.001^{\star}$ \\
\hline
\end{tabular}

Table 5. Relationship between type of treatment and associated intracranial hemorrhage to the outcome.

\begin{tabular}{|c|c|c|c|c|c|c|c|c|c|c|c|}
\hline \multirow{4}{*}{$\begin{array}{l}\text { Associated } \\
\text { intracranial } \\
\text { Hemorrhage }\end{array}$} & \multicolumn{10}{|c|}{ Type of treatment } & \multirow{4}{*}{ p-value } \\
\hline & \multirow{3}{*}{ No. } & \multicolumn{4}{|c|}{$\begin{array}{l}\text { Conservative } \\
\quad(n=10)\end{array}$} & \multirow{3}{*}{ No. } & \multicolumn{4}{|c|}{$\begin{array}{l}\text { Surgical craniotomy } \\
\qquad(\mathrm{n}=10)\end{array}$} & \\
\hline & & \multicolumn{2}{|c|}{$\begin{array}{l}\text { Survival } \\
(\mathrm{n}=6)\end{array}$} & \multicolumn{2}{|c|}{$\begin{array}{l}\text { Dead } \\
(n=4)\end{array}$} & & \multicolumn{2}{|c|}{$\begin{array}{l}\text { Survival } \\
(\mathrm{n}=5)\end{array}$} & \multicolumn{2}{|c|}{$\begin{array}{l}\text { Dead } \\
(n=5)\end{array}$} & \\
\hline & & No. & $\%$ & No. & $\%$ & & No. & $\%$ & No. & $\%$ & \\
\hline IVH & 7 & 4 & 57.1 & 3 & 42.9 & 4 & 1 & 25.0 & 3 & 75.0 & 0.178 \\
\hline $\mathrm{IVH}+\mathrm{SAH}$ & 0 & 0 & 0.0 & 0 & 0.0 & 1 & 1 & 100.0 & 0 & 0.0 & 0.305 \\
\hline
\end{tabular}

Table 6. Complications developed during admission according to type of treatment.

\begin{tabular}{ccccccc}
\hline & & \multicolumn{4}{c}{ Type of treatment } & \\
\cline { 3 - 6 } Complications & No. & \multicolumn{2}{c}{$\begin{array}{c}\text { Conservative } \\
(\mathrm{n}=10)\end{array}$} & $\begin{array}{c}\text { Surgical craniotomy } \\
(\mathrm{n}=10)\end{array}$ & P-value \\
\cline { 3 - 6 } & & No. & $\%$ & No. & $\%$ & \\
Yes & 4 & 1 & 25.0 & 3 & 75.0 & 0.582 \\
No & 16 & 9 & 56.3 & 7 & 43.8 & \\
\hline
\end{tabular}


The mean \pm SD of hospital stay according to type of treatment was more in surgically treated patients $(12.80 \pm 7.77)$, but with no statistical significant difference as shown in Table 7.

Other than the better outcome of surgery in patients with GCS 8-12, we found no significant difference in mortality rate among surgical and conservative groups, (p-value 0.653 ), there was (40\%) mortality in conservative group and (50\%) in surgical group (Table 8).

Case 1: Male patient 35 years not known have any medical disease present with sudden disturbance in conscious level. GCS: 9 with left hemiparesis. Patient treated by surgical craniotomy and evacuation of hematoma. Patient improved postoperative GCS 12 left hemiparesis. After 3 months follow up patient is clinically well GCS 15 left hemiparesis GIV (Figure 1).

Case 2: Female baby two months of age with malnutrition presented with convulsion once attack.

On examination: Full conscious, poor oral intake, Bulge anterior fontanel.

Treated conservatively by dehydrating and anti-epileptics.

Patient discharge after one month's full conscious (Figure 2).

\section{Discussion}

The optimal treatment of primary spontaneous supratentorial intracerebral hemorrhage is controversial [9]. Age was reported to be one of the factors predicting the outcome of patients with SSICH [10]. Kalff et al., [11] reported that lethality raises constantly with age; at 70 years it is $70 \%$, regardless the type of treatment whether it is conservative or operative. On the other hand, Yilmaz et al., [10] reported that the highest mortality rate was observed for patients younger than 55 years (mortality 83\%), followed by patients between 66 and 85 years of age (mortality 70\%). Patients between 56 and 65 years had the best outcome (mortality 50\%). They [10] also stated that elderly patients would be

Table 7. Hospital stay according to type of treatment.

\begin{tabular}{cccc}
\hline & \multicolumn{2}{c}{ Type of treatment } & \\
\cline { 2 - 3 } Hospital stay (days) & $\begin{array}{c}\text { Conservative } \\
(\mathbf{n}=10)\end{array}$ & $\begin{array}{c}\text { Surgical craniotomy } \\
(\mathbf{n}=10)\end{array}$ & P-value \\
\hline Mean \pm SD & $8.70 \pm 8.19$ & $12.80 \pm 7.77$ & 0.172 \\
Median (Range) & $7.0(2.0-30.0)$ & $14.0(2.0-25.0)$ & \\
\hline
\end{tabular}

Table 8. Relationship between patient outcome and type of treatment.

\begin{tabular}{ccccccc}
\hline & & \multicolumn{4}{c}{ Outcome } & \multirow{2}{*}{ P-value } \\
\cline { 3 - 6 } Type of treatment & NO & \multicolumn{2}{c}{$\begin{array}{l}\text { Survival } \\
(\mathbf{n}=11)\end{array}$} & \multicolumn{2}{c}{$\begin{array}{c}\text { Dead } \\
(\mathbf{n}=9)\end{array}$} & \\
\cline { 3 - 6 } & & No. & $\%$ & No. & $\%$ & \\
\hline Conservative & 10 & 6 & 60.0 & 4 & 40.0 & \multirow{2}{*}{0.653} \\
Surgical craniotomy & 10 & 5 & 50.0 & 5 & 50.0 & \\
\hline
\end{tabular}




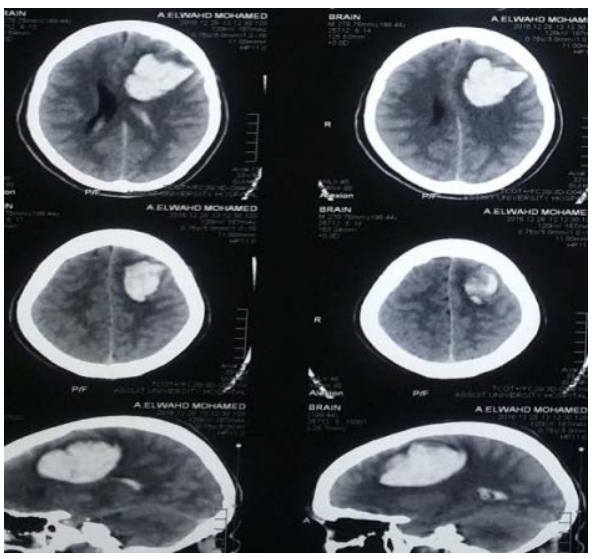

(a)

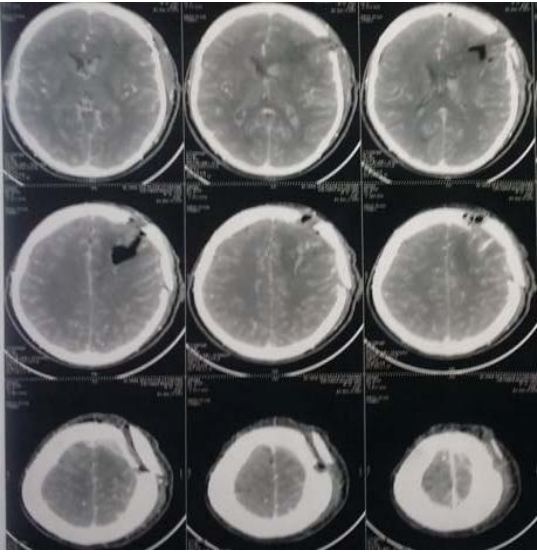

(b)

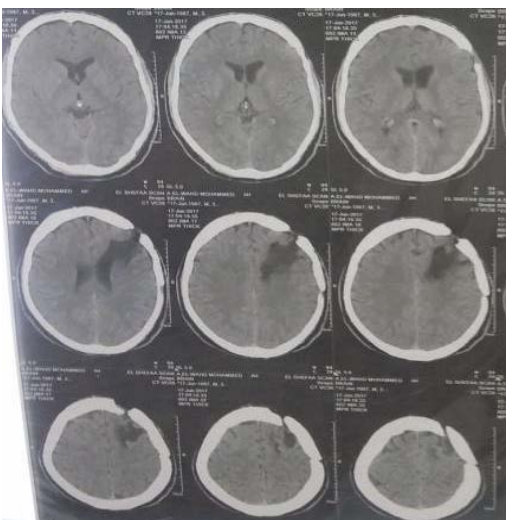

(c)

Figure 1. Case 1: (a) CT brain non contrast at admission, (b) Post operative CT follows up with contrast, (c) CT follow up of brain after 3 months.

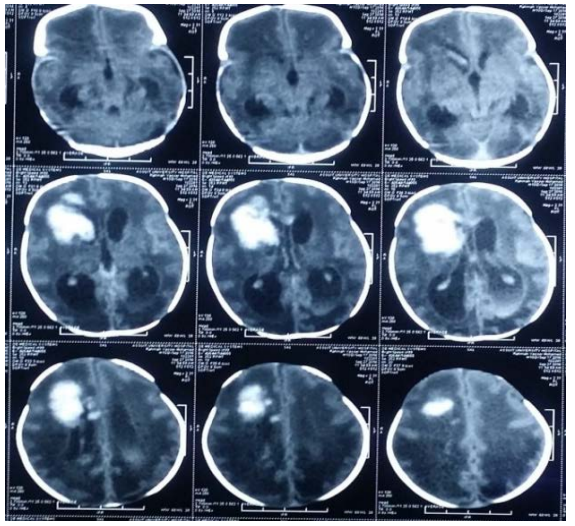

(a)

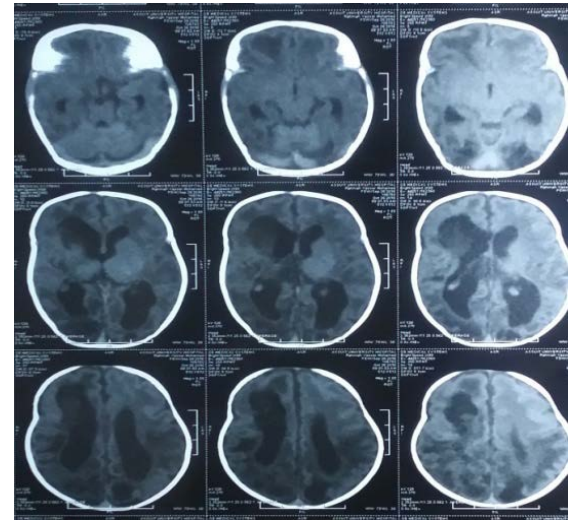

(b)

Figure 2. (a) Non contrast C T brain axial view at admission. (b) CT brain follow up after one months.

expected to have poor outcome from surgery, but it was surprising that the youngest age group had the worst outcome. Cook et al., [12] believe that the older the patients the less unfavorable outcome. Tedeschi et al., [13] thought that the age dose not influence the prognosis, which was the same as our results as we 
found no statistical significant difference in outcome regarding the age as we had 11 cases out of 20 cases above the age 50 years mortality of (45.5\%), in comparison to mortality of (44.4\%) in patient with age less than 50 years.

Regarding the line of treatment we also did not find significant statistical difference between conservative treatment and surgical treatment in outcome regarding the age of patients. Yilmaz et al., [10] preferred to do surgical evacuation of hematoma, in younger patients even they had low GCS, the reasons for that the younger patients the better outcome as they had less co morbidities, which was the important factor in deciding upon surgery of ICH. The same concept we had in our study as 6 cases out of 9 patients with age less than 50 years were treated surgically, and 7 out of 11 patients with age above 50 years were treated conservatively. Regarding the gender, the males were represented two thirds the females in our study (13 males and 7 females, $(65 \%, 35 \%)$ respectively). This result was also reported by An et al., [14] and Giroud et al., [15] as they noted that for all ages the annual incidence rate per 100,000 persons was higher in men than in women. Ikram et al., [16] also reported that the incidence was $15 \%$ lower in women than men. In the other hand Kase et al., [17] and Sliver et al., [18] found that there is slightly female preponderance among spontaneous intracerebral hematomas. Gender did not affect the outcome in our series, Ikram et al., [16] also reported no statistically significant difference regarding the gender. Flaherty et al., [19] reported that hypertension is the most important and prevalent modifiable risk factor for ICH. In our study patients associated with arterial hypertension represented 65\%, this accordance with other studies [14] [20] [21] [22].

Other studies reported another risk factor as Arboix et al, [23] reported diabetes mellitus as an independent risk factor of early mortality while Kurth et al., [24] reported smoking as a risk factor for ICH. Regarding to line of treatment, we found 6 cases of 13 patients with HTN (46\%) treated conservatively with mortality of (50\%), and 7 cases out of 13 patients (54\%) treated surgically with mortality of (57\%), with no any significant difference in outcome (P-value 0.639), which is the same as reported by Yilmaz et al., [10] as they found that hypertension was the most commonly seen disease in patients with ICH (78\%), but it did not have any effect on outcome. Also Kazui et al., [25] found no clear association between high admission blood pressure (SBP $>210 \mathrm{mmHg}$ ) and hematoma expansion or neurological deterioration. In the other hand Tetri et al., [5] noticed that a high mean arterial blood pressure at admission was an independent predictor of early death in ICH patients.

Intraventricular hemorrhage is a much-feared complication of intracerebral hemorrhage, leading to hydrocephalus and associated with poor outcome [9]. Hallevi et al., [26] also noticed that the intraventricular extension of the hematoma (IVH) is an independent predictor of poor outcome in patients with ICH. In our study there were 11 cases (55\%) associated with intraventricular hemorrhage, 7 case (63\%) treated conservatively with mortality of (42\%), and 4 cases 
(37\%) treated surgically which had mortality of $(75 \%)$. but still no statistic significant difference in outcome (p-value 0.178 ). The same results was found by Talukder et al., [27] as they showed no difference in outcome (p-value 0.667 ) of ventricular extension between surgical and conservative group, In other hand Hinson et al., [28] showed that of 902 patients followed up in the Surgical Trial in ICH (STICH), favorable outcomes were reported in (31\%) of those without IVH and $(15 \%)$ with IVH $(P<0.00001)$, also Mendelow et al., [29] reported that the prognosis for patients with intraventricular haemorrhage with or without hydrocephalus is much worse than that for intracerebral haemorrhage alone, and the patients with lobar hematomas and no IVH might benefit from surgery. The most common presentation of our patients was deterioration of the conscious level which reported in 12 cases out of 20 patients (60\%), Pantazis et al., [30] found $42 \%$ of their cases presented with deteriorated consciousness. Cuatico et al., [31] and Talukder et al., [27] stated that the significance of level of consciousness the most important single clinical signs determining the prognosis, the same result we had in our study as we had 5 patients with GCS $\leq 8(25 \%)$ all of them (100\%) died regardless the type of treatment, which indicated that when the initial GCS is less than " 8 " mortality is high, similar results were found by different studies [32] [33] [34] The risk for early neurological deterioration and the high rate of poor long-term outcomes underscores the need for aggressive early management Steiner et al., [35].

Gregson et al., [36] reported that when the GCS is $\leq 8$, early surgery does not significantly improve outcome, this argument further suggests that once the GCS has dropped to $\leq 8$, then irretrievable damage has already occurred and surgery will not be successful in rescuing the patient, in contrast Yilmaz et al., [10] reported that even if the GCS of young patients is low, they are more likely to have surgery as neurosurgeons usually feel that they would have a better outcome as they have less co morbidity. We had 9 patients with GCS " $8-12$ ", seven of them (77\%) were treated surgically, with survival percentage $56 \%$ (five cases) and 2 cases (22\%) died. In other hand the ramming 2 cases with GCS " $8-12$ " (22\%) whom treated conservatively died, we found a statistic significant that support the idea of good outcome with surgery in this group of patients with a GCS of $8-12$, comparing with their corresponding medical group. similar results have been reported by Auer et al., [37] and Kaya et al., [38].

Gregson et al., [36] found that the patients in a coma had a poorer outcome than conscious patients: $95 \%$ of patients with a GCS $\leq 8$ had an unfavorable outcome compared with $81 \%$ of patients with a GCS of $9 \%$ to $12 \%$, and $60 \%$ of patients with a GCS of 13 to 15, they [36] also reported that the early surgery may improve the outcome of patients with Glasgow Coma Scale 9 to 12, hematoma volume of 20 to $50 \mathrm{ml}$, and perhaps those with superficial hematomas without intraventricular blood. We had 6 cases (30\%) with GCS 15 there were treated conservatively and all of them survived (p-value 0.003), Sun et al., [9] also report that the admission conscious level and the size of the hematoma were 
more favorable in the conservatively managed patients. It is logical to treat conservatively the patient with a good initial conscious level. Takeuchi et al., [13] said that a statistical analysis showed that the GCS score at admission was significantly higher in the favorable outcome group than that in the poor outcome group.

Inagawa et al., [39] reported that no relation of incidence rate of $\mathrm{ICH}$ to the site of ICH, Talukder et al., [27] noticed that location of the hematoma did not influence the outcome. In our study there was no any statistical significant difference between the location of the hematoma and type of treatment to outcome, but frontal and parietal location had relatively better outcome than other locations.

Pantazis et al., [30] reported that It is possible that early mortality is most directly related to severity of hemorrhage where as mortality rate influenced more dramatically by a patients general medical conditions and complications, and they (27) noticed that the most important cause of death was the direct effect of the hemorrhage per se (41 patients, $72 \%$ ), and late causes of death included pneumonia, pulmonary embolism, and renal failure In our study we demonstrated that the complications were slightly more with surgical group but with no statistical significant difference between both groups (p-value 0.582 ).

In our series there was no significant difference in the in-hospital stay between surgical and conservative treatment ( $\mathrm{p}$-value 0.172 ), but we noticed the mean \pm SD of in-hospital stay was long in surgically treated patients $(12.80 \pm 7.77)$, in contrast to conservative group (the mean \pm SD $8.70 \pm 8.19$ ). Kim et al., [40] found a significant difference in the in-hospital stay between the conservative group (13.93 days, SD 8.8 days) and the surgical group (20.33 days, SD 6.3 days; $\mathrm{p}=0.001$ ), and they explained this difference due to early death in conservative treatment group resulted in a shortened inpatient stay.

In general speaking, other than the better outcome of surgery in patients with GCS 8 - 12, we found no significant difference in mortality rate among surgical and conservative groups, ( $\mathrm{p}$-value 0.653 ), there was (40\%) mortality in conservative group and (50\%) in surgical group. Mendelow et al., [34] STICH trial, it was suggested that early surgery could be beneficial in certain patients with superficial lobar hemorrhages, but there was no overall statistically significant difference in the mortality or functional outcome between the early surgery and initial conservative treatment groups. Zuccarello et al., [41] also reported that there was no significant difference in mortality at 3 months between the 2 groups. In the other hand Hoff et al., [42] reported that there was marginal benefit for the early surgical group over the conservative group when the ICH was lobar in location, while Sun et al., [9] reported that the conservatively managed patients achieved an overall better outcome compared with the surgical groups.

\section{Conclusion}

After analyzing the results, we found that when the GCS was " 8 - 12", surgical 
intervension was recommended and carried a better prognosis than waiting for the conservative treatment. When GCS was higher $(>12)$, conservative treatment can be the favorable option. Otherwise, we found no statistical difference between surgical and conservative treatment in the treatment of spontaneous primary ICH. Further studies with bigger number of patients and longer period of follow-up are recommended.

\section{Acknowledgements}

To Dr. Salah Abdullah Musaed Hussein, resident of neurosurgery, Assiut University for his efforts in data collection.

\section{Conflicts of Interest}

The authors declare no conflicts of interest regarding the publication of this paper.

\section{References}

[1] Trabert, J. and Steiner, T. (2012) Medical versus Surgical Management of Intracerebral Hematomas. Current Atherosclerosis Reports, 14, 366-372. https://doi.org/10.1007/s11883-012-0259-7

[2] Woo, D. and Broderick, J.P. (2002) Spontaneous Intracerebral Hemorrhage: Epidemiology and Clinical Presentation. Neurosurgery Clinics of North America, 13, 265-279. https://doi.org/10.1016/S1042-3680(02)00011-6

[3] Qureshi, A.I., Tuhrim, S., Broderick, J.P., Batjer, H.H., Hondo, H. and Hanley, D.F. (2001) Spontaneous Intracerebral Hemorrhage. New England Journal of Medicine, 344, 1450-1460. https://doi.org/10.1056/NEJM200105103441907

[4] Ariesen, M., Claus, S.P., Rinkel, G.J.E. and Algra, A. (2003) Risk Factors for Intracerebral Hemorrhage in the General Population: A Systematic Review. Stroke, 34, 2060-2065. https://doi.org/10.1161/01.STR.0000080678.09344.8D

[5] Tetri, S. (2009) Factors Affecting Outcome after Primary Intracerebral Hemorrhage. Oulun yliopisto.

[6] Sessa, M. (2008) Intracerebral Hemorrhage and Hypertension. Neurological Sciences, 29, 258-259. https://doi.org/10.1007/s10072-008-0956-8

[7] Hemphill, J.C., Greenberg, S.M., Anderson, C.S., Becker, K., Bendok, B.R., Cushman, M., Scott, P.A., et al. (2015) Guidelines for the Management of Spontaneous Intracerebral Hemorrhage: A Guideline for Healthcare Professionals from the American Heart Association/American Stroke Association. Stroke, 46, 2032-2060. https://doi.org/10.1161/STR.0000000000000069

[8] Wang, E., Ho, C.L., Lee, K.K., Ng, I. and Ang, B.T. (2008) Changes in Brain Biochemistry and Oxygenation in the Zone Surrounding Primary Intracerebral Hemorrhage. Acta Neurochirurgica Supplements, 102, 293-297. https://doi.org/10.1007/978-3-211-85578-2_55

[9] Sun, D.T.F., Tsang, Y.Y.Y. and Poon, W.S. (2004) Intracerebral Haematoma: Operative versus Non Operative. Annals of the College of Surgeons of Hong Kong, 8, 55-58. https://doi.org/10.1111/j.1442-2034.2004.00203.x

[10] Yilmaz, C., Kabatas, S., Gulsen, S., Cansever, T., Gurkanlar, D., Caner, H. and Altinors, N. (2010) Spontaneous Supratentorial Intracerebral Hemorrhage: Does Sur- 
gery Benefit Comatose Patients? Annals of Indian Academy of Neurology, 13, 184. https://doi.org/10.4103/0972-2327.70881

[11] Kalff, R., Feldges, A., Mehdorn, H.M. and Grote, W. (1992) Spontaneous Intracerebral Hemorrhage. Neurosurgical Review, 15, 177-186.

https://doi.org/10.1007/BF00345928

[12] Cook, A.W., Plaut, M. and Browder, J. (1965) Spontaneous Intracerebral Hemorrhage. Archives of Neurology, 13, 25-29. https://doi.org/10.1001/archneur.1965.00470010029004

[13] Takeuchi, S., Takasato, Y., Masaoka, H., Hayakawa, T., Yatsushige, H., Shigeta, K., Nagatani, K., Otani, N., et al. (2013) Decompressive Craniectomy with Hematoma Evacuation for Large Hemispheric Hypertensive Intracerebral Hemorrhage. Acta Neurochirurgica Supplement, 9, 118-277. https://doi.org/10.1007/978-3-7091-1434-6_53

[14] An, S.J., Kim, T.J. and Yoon, B.W. (2017) Epidemiology, Risk Factors, and Clinical Features of Intracerebral Hemorrhage: An Update. Journal of Stroke, 19, 3. https://doi.org/10.5853/jos.2016.00864

[15] Giroud, M., Gras, P., Chadan, N., Beuriat, P., Milan, C., Arveux, P. and Dumas, R. (1991) Cerebral Haemorrhage in a French Prospective Population Study. Journal of Neurology, Neurosurgery \& Psychiatry, 54, 595-598. https://doi.org/10.1136/jnnp.54.7.595

[16] Ikram, M.A., Wieberdink, R.G. and Koudstaal, P.J. (2012) International Epidemiology of Intracerebral Hemorrhage. Current Atherosclerosis Reports, 14, 300-306. https://doi.org/10.1007/s11883-012-0252-1

[17] Kase, C.S. (2009) Clinical Presentation of Intracerebral Hemorrhage. Cambridge University Press, New York, 101-120. https://doi.org/10.1017/CBO9780511691836.009

[18] Silver, F.L., Norris, J.W., Lewis, A.J. and Hachinski, V.C. (1984) Early Mortality Following Stroke: A Prospective Review. Stroke, 15, 492-496. https://doi.org/10.1161/01.STR.15.3.492

[19] Flaherty, M.L., Woo, D. and Broderick, J.P. (2010) The Epidemiology of Intracerebral Hemorrhage.

[20] Sturgeon, J.D., Folsom, A.R., Jr., W.T.L., Shahar, E., Rosamond, W.D. and Cushman, M. (2007) Risk Factors for Intracerebral Hemorrhage in a Pooled Prospective Study. Stroke, 38, 2718-2725. https://doi.org/10.1161/STROKEAHA.107.487090

[21] Ko, S., Choi, H.A. and Lee, K. (2012) Clinical Syndromes and Management of Intracerebral Hemorrhage. Current Atherosclerosis Reports, 14, 307-313. https://doi.org/10.1007/s11883-012-0251-2

[22] Neau, J.P., Ingrand, P., Couderq, C., Rosier, M.P., Dumas, P., Vandermarcq, P., Gil, R., et al. (1997) Recurrent Intracerebral Hemorrhage. Neurology, 49, 106-113. https://doi.org/10.1212/WNL.49.1.106

[23] Arboix, A., Massons, J., García-Eroles, L.U.Í.S., Oliveres, M. and Targa, C. (2000) Diabetes Is an Independent Risk Factor for In-Hospital Mortality from Acute Spontaneous Intracerebral Hemorrhage. Diabetes Care, 23, 1527-1532. https://doi.org/10.2337/diacare.23.10.1527

[24] Kurth, T., Kase, C.S., Berger, K., Gaziano, J.M., Cook, N.R. and Buring, J.E. (2003) Smoking and Risk of Hemorrhagic Stroke in Women. Stroke, 34, 2792-2795. https://doi.org/10.1161/01.STR.0000100165.36466.95

[25] Kazui, S., Naritomi, H., Yamamoto, H., Sawada, T. and Yamaguchi, T. (1996) En- 
largement of Spontaneous Intracerebral Hemorrhage. Stroke, 27, 1783-1787. https://doi.org/10.1161/01.STR.27.10.1783

[26] Hallevi, H., Albright, K.C., Aronowski, J., Barreto, A.D., Martin-Schild, S., Khaja, A.M., Grotta, J.C., et al. (2008) Intraventricular Hemorrhage Anatomic Relationships and Clinical Implications. Neurology, 70, 848-852. https://doi.org/10.1212/01.wnl.0000304930.47751.75

[27] Talukder, M.M.H., Islam, K.M.T., Hossain, M., Jahan, M.U., Mahmood, F. and Hossain, S.S. (2013) Surgery for Primary Intracerebral Haemorrhage: Is It Safe and Effective? Bangladesh Medical Research Council Bulletin, 38, 74-78. https://doi.org/10.3329/bmrcb.v38i3.14328

[28] Hinson, H.E., Hanley, D.F. and Ziai, W.C. (2010) Management of Intraventricular Hemorrhage. Current Neurology and Neuroscience Reports, 10, 73-82. https://doi.org/10.1007/s11910-010-0086-6

[29] Mendelow, A.D., Gregson, B.A., Rowan, E.N., Murray, G.D., Gholkar, A., Mitchell, P.M. and STICH II Investigators (2013) Early Surgery versus Initial Conservative Treatment in Patients with Spontaneous Supratentorial Lobar Intracerebral Haematomas (STICH II): A Randomized Trial. The Lancet, 382, 397-340. https://doi.org/10.1016/S0140-6736(13)60986-1

[30] Pantazis, G., Tsitsopoulos, P., Mihas, C., Katsiva, V., Stavrianos, V. and Zymaris, S. (2006) Early Surgical Treatment vs Conservative Management for Spontaneous Supratentorial Intracerebral Hematomas: A Prospective Randomized Study. Surgical Neurology, 66, 492-501. https://doi.org/10.1016/j.surneu.2006.05.054

[31] Cuatico, W., Adib, S. and Gaston, P. (1965) Spontaneous Intracerebral Hematomas: A Surgical Appraisal. Journal of Neurosurgery, 22, 569-575. https://doi.org/10.3171/jns.1965.22.6.0569

[32] Go, G.O., et al. (2013) The Outcomes of Spontaneous Intracerebral Hemorrhage in Young Adults: A Clinical Study. Journal of Cerebrovascular and Endovascular Neurosurgery, 15, 214-220.

[33] Rehman, W.A. and Anwar, M.S. (2017) Surgical Outcome of Spontaneous Supra Tentorial Intracerebral Hemorrhage. Pakistan Journal of Medical Sciences, 33, 804. https://doi.org/10.12669/pjms.334.12172

[34] Mendelow, A.D., Gregson, B.A., Fernandes, H.M., Murray, G.D., Teasdale, G.M., Hope, D.T. and STICH Investigators (2005) Early Surgery versus Initial Conservative Treatment in Patients with Spontaneous Supratentorial Intracerebral Haematomas in the International Surgical Trial in Intracerebral Haemorrhage (STICH): A Randomised Trial. The Lancet, 365, 387-397. https://doi.org/10.1016/S0140-6736(05)70233-6

[35] Steiner, T., Diringer, M.N., Schneider, D., Mayer, S.A., Begtrup, K., Broderick, J., Davis, S.M., et al. (2006) Dynamics of Intraventricular Hemorrhage in Patients with Spontaneous Intracerebral Hemorrhage: Risk Factors, Clinical Impact, and Effect of Hemostatic Therapy with Recombinant Activated Factor VII. Neurosurgery, 59, 767-774. https://doi.org/10.1227/01.NEU.0000232837.34992.32

[36] Gregson, B.A., Murray, G.D., Mitchell, P.M., Rowan, E.N., Gholkar, A.R. and Mendelow, A.D. (2012) Update on the Surgical Trial in Lobar Intracerebral Haemorrhage (STICH II): Statistical Analysis Plan. Trials, 13, 222. https://doi.org/10.1186/1745-6215-13-222

[37] Auer, L.M., Deinsberger, W., Niederkorn, K., Gell, G., Kleinert, R., Schneider, G., Kleinert, G., et al. (1989) Endoscopic Surgery versus Medical Treatment for Spontaneous Intracerebral Hematoma: A Randomized Study. Journal of Neurosurgery, 
70, 530-535. https://doi.org/10.3171/jns.1989.70.4.0530

[38] Kaya, R.A., Türkmenoğlu, O., Ziyal, I.M., Dalkiliç, T., Sahin, Y. and Aydin, Y. (2003) The Effects on Prognosis of Surgical Treatment of Hypertensive Putaminal Hematomas through Transsylvian Transinsular Approach. Surgical Neurology, 59, 176-183. https://doi.org/10.1016/S0090-3019(02)01043-1

[39] Inagawa, T., Ohbayashi, N., Takechi, A., Shibukawa, M. and Yahara, K. (2003) Primary Intracerebral Hemorrhage in Izumo City, Japan: Incidence Rates and Outcome in Relation to the Site of Hemorrhage. Neurosurgery, 53, 1283-1298. https://doi.org/10.1227/01.NEU.0000093825.04365.F3

[40] Kim, H.T., Lee, J.M., Koh, E.J. and Choi, H.Y. (2015) Surgery versus Conservative Treatment for Spontaneous Supratentorial Intracerebral Hemorrhage in Spot Sign Positive Patients. Journal of Korean Neurosurgical Society, 58, 309-315. https://doi.org/10.3340/jkns.2015.58.4.309

[41] Zuccarello, M., Brott, T., Derex, L., Kothari, R., Sauerbeck, L., Tew, J. and Broderick, J. (1999) Early Surgical Treatment for Supratentorial Intracerebral Hemorrhage: A Randomized Feasibility Study. Stroke, 30, 1833-1839. https://doi.org/10.1161/01.STR.30.9.1833

[42] Hoff, J.T., Keep, R.F., Xi, G. and Hua, Y. (2006) Brain Edema XIII. Acta Neurochirurgica Supplementum, 96, 17-20.

\section{Abbreviations}

SSICH: Spontaneous superficial intracerebral hematoma. DCL: Disturbance in conscious level. GCS: Glasgow coma scale IVH: Intraventricular hemorrhage. SAH: Subarachnoid hemorrhage. HTN: Hypertension. CT: Computerized tomography. 